to suggest that starvation decreases the resistance of experimental animals to Gram-negative enteric infections, and overeating is known to play an essential part in the development of enterotoxaemia in sheep and possibly in man (Freter, 1955; Bullen and Scarisbrick, 1957; Formal et al., 1958; Murrell and Roth, 1963; Murrell et al., 1966).

In-vivo experiments are at present being planned with a view to producing a breast-fed type of faecal flora and large bowel environment in bottle-fed babies.

Sir James Howie suggested this problem to us and we are grateful for his interest and encouragement in the work. We are greatly indebted to Dr. J. D. Hall, Miss W. Parr, and Sister A. Bourne, who arranged for us to receive samples of infant faeces; and Messrs. Unigate and Messrs. Trufood for suppyling dried cow's milk preparations. Our thanks are also due to Mr. M. G. Day, who kindy performed some of the chemical investigations, and to Mrs. K. Williams for invaluable technical assistance.

\section{References}

Alexander, M. B. (1948). British Medical fournal, 2, 973. Bullen, J. J., and Scarisbrick, R. (1957). Fournal of Pathology and Bacteriology,

Formal, S. B., Dammin, G. J., La Brec, E. H., and Schneider, H. (1958). fournal of Bacteriology, 75, 604 .

Freter, R. (1955). Fournal of Infectious Diseases, 97, 57.

György, P., Norris, R. F., and Rose, C. S. (1954). Archives of Biochemistry and Biophysics, 48, 193.

Hinton, N. A., and MacGregor, R. R. (1958). Canadian Medical Association Fournal, 79, 359.

Lancet, 1971, 1, 30.

Miles, A. A., Misra, S. S., and Irwin, J. O. (1938). fournal of Hygiene,

38, 732. G. C., and Roth, L. (1963). Medical fournal of Australia, 1,61 .

Murrell, T. G. C., Egerton, J. R., Rampling, A., Samels, J., and Walker, P. D. (1966). Fournal of Hygiene, 64, 375.

Neter, E. (1959). Fournal of Pediatrics, 55, 223.
Oser, B. L. (1965). Hawk's Physiological Chemistry, 14th edn., p. 369. New York, McGraw-Hill.

Ross, C. A. C., and Dawes, E. A. (1954). Lancet, 1, 994.

Sussman, S. (1961). Pediatrics, 27, 308.

\title{
Potentially Serious Side Effects of High-dose Twice-weekly Rifampicin
}

\author{
GRAHAM POOLE, PETER STRADLING, SHEILA WORLLEDGE
}

British Medical fournal, 1971, 3, 343-347

\section{Summary}

Daily rifampicin in a single dose of $600 \mathrm{mg}$, combined with other drugs, usually streptomycin and isoniazid, was given to 49 patients for three months. It was planned to continue for another 15 months with twice-weekly rifampicin $1,200 \mathrm{mg}$ plus isoniazid $900 \mathrm{mg}$, but the high incidence of side effects led to cessation of the intermittent regimen when only two patients had completed 18 months.

Though there was no serious problem with daily treatment 11 patients $(22 \%)$ were unable to continue rifampicin on the intermittent regimen. In $8(16 \%)$ a pyrexial syndrome occurred. In one of these patients there was also temporary renal failure, and in another precipitous thrombocytopenia led to epistaxis and bleeding into the tongue and lips. Symptomless thrombocytopenia developed in two other patients, making three cases $(6 \%)$ of thrombocytopenia in all.

In $16(33 \%)$ of the 49 patients antibodies to rifampicin were detected in the blood. Side effects occurred in 9 $(56 \%)$ of these, including the three developing thrombocytopenia, but in only $2(6 \%)$ of the 33 patients with no antibodies detected. This association of toxic reactions with antibodies is highly significant $(\mathbf{P}<0.001)$.

\section{Introduction}

Laboratory reports on rifampicin suggest that it is one of the most effective antituberculosis drugs yet discovered (Verbist and Gyselen, 1968), and clinical results are highly encouraging Royal Postgraduate Medical School, Hammersmith Hospital, London
W12 OHS

GRAHAM POOLE, M.B., M.R.C.P., Lecturer in Respiratory Diseases

PETER STRADLING, M.D., F.R.C.P., Senior Lecturer in Respiratory Diseases

SHFII.A WORLLEDGE, M.B., F.R.C.PATH., Senior Lecturer in Haematology
(Gyselen et al., 1969). The only appreciable side effect reported when the drug is used on a daily basis is jaundice, which is particularly likely to occur in alcoholics (Lesobre et al., 1969; Lees et al., 1970). Laboratory work further suggests that rifampicin should be highly effective in intermittent regimens (Batten, 1969; Grumbach et al., 1969; Dickinson and Mitchison, 1970).

We started a clinical trial of intermittent rifampicin therapy in the summer of 1969 . This preliminary report on side effects of rifampicin is made to warn others that our experience suggests that rifampicin, when used twice-weekly at a dosage of $1,200 \mathrm{mg}$, can result in an unacceptably high incidence of toxicity. One side effect encountered (thrombocytopenia) is potentially extremely serious and was first recognized by Farga (1970). A case of immune thrombocytopenia with rifampicin antibodies detected by reaction with platelets and red cells has already been reported from this school (Blajchman et al., 1970), and two more have subsequently occurred, together with a case of transient renal failure.

\section{Materials and Methods}

REGIMEN

The trial regimen planned, and used in most cases, was intramuscular streptomycin $0.75 \mathrm{~g}$, oral isoniazid $300 \mathrm{mg}$, and oral rifampicin $600 \mathrm{mg}$ on six days a week for three months, followed by twice-weekly rifampicin $1,200 \mathrm{mg}$, with isoniazid $900 \mathrm{mg}$, plus pyridoxine $10 \mathrm{mg}$ for a further 15 months. Appropriate dosage adjustments were made for the two children in the series. Administration of all doses to all patients was fully supervised.

\section{PATIENTS}

All newly-diagnosed tuberculous patients with tuberculosis attending the chest clinic at Hammersmith Hospital from 1 July 1969 were considered for inclusion in the trial. Also included in this toxicity study were three patients who received, 
for retreatment of relapsed disease, regimens including rifampicin plus ethambutol and, as a third drug, either isoniazid or streptomycin or capreomycin. New patients with alcoholism, proved liver disease, or pregnancy, or who were only temporarily resident in the area, were not treated with rifampicin. In addition two patients were not included because they were receiving large doses of steroid and immunosuppressive therapy after renal transplant operations, which may well have materially altered the response to rifampicin.

The report includes only those patients who had completed at least four months of treatment, the range being from 4 to 18 months; only two patients completed the planned 18 months.

The 49 patients in the survey ( 33 males and 16 females aged 9-84 years) came from various racial groups (Tables I and II). Immigrants accounted for $61 \%$ (Asians and Negroes 37\%, Caucasians 24\%).

TABLE I-Age and sex distribution of the patients treated with rifampicin. The number of patients developing rifampicin-dependent antibodies is shown in parentheses

\begin{tabular}{|c|c|c|c|c|c|c|}
\hline \multicolumn{3}{|c|}{ Age Groups } & Males & Females & \multicolumn{2}{|c|}{ Total } \\
\hline $\begin{array}{r}9-20 \\
21-30 \\
31-40 \\
41-50 \\
51-60 \\
61+ \\
\end{array}$ & $\begin{array}{l}. \\
\cdots \\
\cdots \\
\cdots \\
\cdots\end{array}$ & $\begin{array}{l}. \\
\because \\
\because \\
\cdots \\
\end{array}$ & $\begin{array}{ll}2 & \\
6 & (4) \\
8 & (2) \\
7 & \\
9 & (1) \\
1 & \\
\end{array}$ & $\begin{array}{ll}1 & (1) \\
2 & (1) \\
3 & (1) \\
5 & (3) \\
2 & (1) \\
3 & (2) \\
\end{array}$ & $\begin{array}{r}3 \\
8 \\
11 \\
12 \\
11 \\
4 \\
\end{array}$ & $\begin{array}{l}(1) \\
(5) \\
(3) \\
(3) \\
(2) \\
(2) \\
\end{array}$ \\
\hline & Total & $\ldots$ & $33(7)$ & $16(9)$ & 49 & (16) \\
\hline
\end{tabular}

TABLE II-Country of origin of the patients treated with rifampicin. The number of patients developing rifampicin-dependent antibodies is shown in parentheses

\begin{tabular}{c|c|c|c|c|c}
\hline \multicolumn{1}{c|}{ British } & Irish & Asian & African & W. Indian & Other European \\
\hline 19 (6) & 7 (2) & 6 (1) & 1 & 11 (6) & 5 (1) \\
\hline
\end{tabular}

Thirty-seven patients with tuberculosis (30 males and 7 females) attending other units and receiving drugs other than rifampicin were used as controls. The age and racial distribution was similar to that in the rifampicin group; immigrants again comprised $61 \%$.

\section{TOXICITY PRECAUTIONS}

If pregnancy occurred during treatment rifampicin was stopped. Bilirubin, alkaline phosphatase, and isocitric dehydrogenase estimations were done routinely on pretreatment blood samples, and again three to four weeks after treatment had started. Patients were also warned to report any untoward symptoms, particularly nausea, itching, or acheing in the upper abdomen. Inquiries for any possible toxic symptoms were routinely made by the nurses administering the treatment, and the eyes were examined regularly for jaundice. Hepatotoxicity is not considered further here, except to state that no patients developing the side effects described in this paper suffered hepatotoxic reactions.

\section{DIRECT ANTIGLOBULIN TESTS}

These were carried out as a screening procedure by testing the patient's red blood cells with a broad-spectrum antiglobulin serum used in two dilutions. The dilutions chosen were those that had previously been determined as optimal for detecting complement and IgG respectively when bound to the red cells. Any positive results were further tested by standard techniques with an anti-IgG serum, an anti-IgM serum, an anti-IgA serum, and an anti-complement serum (Dacie and Lewis, 1968).

\section{INDIRECT ANTIGLOBULIN TESTS}

These were also carried out as a screening procedure, the method described by Harris (1956) being used. A total of $70 \mathrm{mg}$ of purified rifampicin (kindly supplied by Professor D. A. Mitchison), or the rifampicin from the capsules, was dissolved in $100 \mathrm{ml}$ of $0.95 \%$ sodium chloride and added to an equal volume of the patient's serum. (There was no difference in the results when using either of these two solutions of rifampicin.) The tests were read with a broad-spectrum antiglobulin serum used in the two dilutions described above. In a control test saline was substituted for rifampicin. The $\mathrm{pH}$ activities of the rifampicin solution and the saline were the same.

The serum for all the indirect antiglobulin tests was separated from the red cells within four hours of taking the sample. The serum was either tested at once or frozen to $-20^{\circ} \mathrm{C}$ and tested within 24 hours. The normal red cells used in the screening procedure were the group 0 red cells that are prepared daily in our laboratory for the detection of atypical blood group antibodies.

\section{HAEMATOLOGICAL TESTS}

Platelet complement fixation tests were carried out as previously described (Blajchman et al., 1970). The patients in the rifampicin group had full blood counts, including platelet estimations, done at monthly intervals. Two samples were taken each time; one just before the rifampicin was given and one six hours later.

\section{Results}

All the patients on rifampicin did remarkably well clinically. There were $37(76 \%)$ from whom Mycobacterium tuberculosis was isolated-33 $(89 \%)$ converted in eight weeks, and all in 24 weeks. The majority accepted rifampicin with equanimity on a daily basis during the initial three months. The situation became very different, however, during the subsequent intermittent regimen.

A total of 11 patients $(22 \%)$ were unable to continue rifampicin because of side effects developing on intermittent treatment. These side effects were of two types-a febrile reaction occurring in $8(16 \%)$ patients, and thrombocytopenia occurring in $3(6 \%)$. (One patient had both the febrile reaction and thrombocytopenia.) Another patient complained of persistent nausea and slight malaise but did not suffer the febrile reaction or other symptoms.

\section{FEBRILE REACTION}

This clinical syndrome has become clearly recognizable and has been established as directly due to rifampicin by administering $600-\mathrm{mg}$ trial doses of this drug alone to each patient. Pyrexia- $99^{\circ}-105^{\circ} \mathrm{F}\left(37 \cdot 2^{\circ}-40 \cdot 5^{\circ} \mathrm{C}\right)$-for up to 24 hours and malaise occurred in all eight patients at two-and-a-half to four hours after the dose. Rigors occurred in seven; nausea occurred in three, with vomiting in two; and myalgia was prominent in two. A sharp rise in blood pressure occurred in two patients (from $130 / 80$ to $240 / 130 \mathrm{~mm} \mathrm{Hg}$ in one, and from $180 / 110$ to $200 / 140 \mathrm{~mm} \mathrm{Hg}$ in the other). The first of these had temporary renal failure (blood urea $270 \mathrm{mg} / 100 \mathrm{ml}$ ) but responded in a few days to methyldopa and diuretics. Whether the renal failure was a result of an antigen-antibody reaction or a direct toxic effect of the drug or consequent on dehydration due to the vomiting is not known. The last explanation seems improbable on clinical grounds.

\section{THROMBOCYTOPENIA}

Thrombocytopenia occurred in three patients $(6 \%)$. One case 
already reported (Blajchman et al., 1970) presented with epistaxis and bleeding into the lips and tongue. In the other two the monthly determinations of platelets levels showed drug related platelet falls but without symptoms. The platelet level fell, after trial doses of rifampicin, from 147,000 to $29,000 \mathrm{~mm}^{3}$ and from 120,000 to $12,000 \mathrm{~mm}^{3}$ respectively; rifampicin was therefore withdrawn in spite of the absence of symptoms.

\section{DIRECT ANTIGLOBULIN TEST}

The red cells of the patient with thrombocytopenia whose case was previously reported gave a moderately strong positive direct antiglobulin test. However, the red cells of the other two patients who developed symptomless falls in their platelet counts did not show significantly positive results. It has been previously shown that the red cells in $8 \%$ of samples from hospital patients give weakly positive results in this test (Dacie and Worlledge, 1969). Similar results were found when the red cells of this series of patients were tested. These positive results, which were not consistently present in any one patient, did not correlate in any way with the presence or absence of symptoms, and this test was abandoned as a routine procedure half-way through the investigation.

\section{INDIRECT ANTIGLOBULIN TEST}

By using the serum from patients on rifampicin this test gave a positive result in the presence of rifampicin, but not in its absence, in 16 patients $(33 \%)$. It did not give a similar positive result in any sera from patients in the control group. Further tests with the sera of patients who gave rifampicin-dependent positive reactions showed that the positive results were due to complement components bound to the red cell surface. It was presumed that this complement had been bound by rifampicin antibodies in the presence of the drug. These rifampicindependent antibodies did not show any blood group specificity. Provided the drug was also present they reacted equally well with the patient's own cells and with each of the red cell samples from seven donors specially chosen to show blood group specificity.

In five patients rifampicin-dependent antibodies were detected in the serum taken on one occasion only; samples were not available for further tests. The sera from the remaining 11 patients gave positive results with samples taken on more than one occasion, and several patients were sampled many times. The average number of samples taken from the patients on rifampicin, both with and without antibodies, was four. Samples were taken from the control patients on only one occasion.

The sera of three of the $\mathbf{4 9}$ patients on rifampicin contained atypical blood group antibodies and gave positive results in the indirect antiglobulin test with both added rifampicin and added saline. The sera of three of the 37 patients in the control group reacted in the same way (Table III). These antibodies all had the specificity of anti-Lewis. Patients with blood group antibodies were retested for rifampicin antibodies with Le(a-b-)red cells.

TABLE III-Results of testing the serum of patients suffering from tuberculosis for antibodies. The tests were done by the indirect antiglobulin technique with normal red cells both in the presence and in the absence of excess rifampicin

\begin{tabular}{c|c|c}
\hline & $\begin{array}{c}\text { Rifampicin } \\
\text { Included in } \\
\text { Regimen }\end{array}$ & $\begin{array}{c}\text { Rifampicin } \\
\text { Not Included } \\
\text { in Regimen }\end{array}$ \\
\hline Total No. of patients & 49 & 37 \\
\hline $\begin{array}{l}\text { No. with rifampicin-dependent antibodies } \\
\text { No. with blood group antibodies }\end{array}$ & $\begin{array}{c}16(33 \%) \\
\text {.. }\end{array}$ & \begin{tabular}{c}
0 \\
\hline
\end{tabular} \\
\hline
\end{tabular}

\section{PLATELET COMPLEMENT FIXATION TEST}

This test was positive when the serum of the patient with thrombocytopenia previously reported was used. However, the sera of the two other patients, who developed symptomless falls in their platelet count, did not show positive results. Similarly, no positive reactions were obtained in this test with the sera from any of the other patients.

\section{RIFAMPICIN-DEPENDENT ANTIBODIES AND CLINICAL FEATURES}

Rifampicin-dependent antibodies were detected in 16 patients $(33 \%)$; they occurred in all the age groups (Table I). There is a suggestion that females developed antibodies more readily than males $(56 \%, \mathrm{P}<0.01$, and $21 \%, \mathrm{P}<0.05)$. The antibodies also appeared whatever the patient's country of origin, apparently more often in West Indians (Table II).

As is evident from Table IV, side effects occurred in $9(56 \%)$ of the 16 patients with antibodies but in only $2(6 \%)$ of the 33 patients with no antibodies detected. This association is highly significant $(P<0.001)$. In Fig. 1 the side effects are related to the month of treatment at which these effects first appeared and the time of detection of the rifampicin-dependent antibodies. Of the two patients in whom no antibodies were detected one had the typical febrile syndrome and one complained of nausea only. In five patients antibodies were found the first time the patient was tested. In four patients the first tests were negative and antibodies appeared later. It is seen that antibodies could appear before the onset of side effects.

TABLE IV-Association between the occurrence of side effects in the patients and the detection of rifampicin-dependent antibodies in their sera

\begin{tabular}{|c|c|c|c|c|c|}
\hline & & & \multicolumn{2}{|c|}{ Side Effects } & \multirow{2}{*}{ Total } \\
\hline & & & Present & Absent & \\
\hline \multirow[t]{2}{*}{$\begin{array}{c}\text { Antibodies: } \\
\text { Present } \\
\text { Absent }\end{array}$} & & 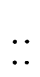 & $\begin{array}{l}9 \\
2\end{array}$ & $\begin{array}{r}7 \\
31\end{array}$ & $\begin{array}{l}16 \\
33\end{array}$ \\
\hline & Total & $\ldots$ & 11 & 38 & 49 \\
\hline
\end{tabular}

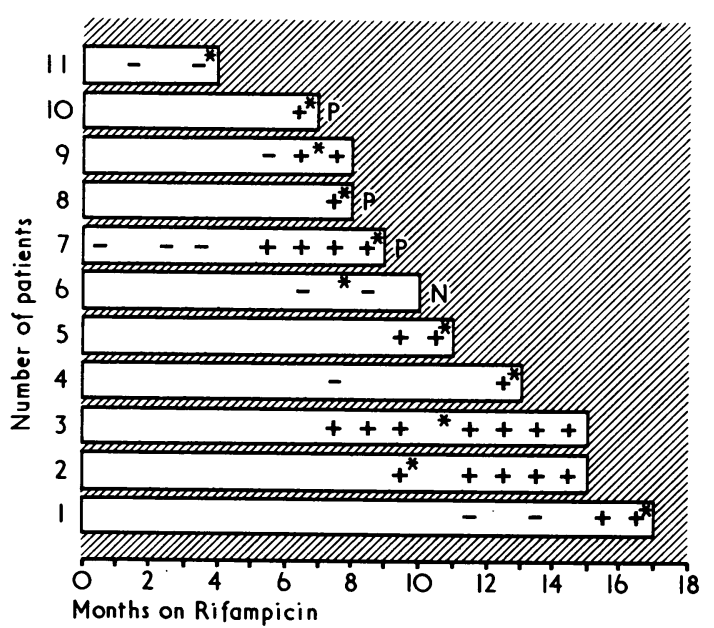

FIG 1.-Shows duration of treatment in 11 patients with side effects and relates the month of treatment in which these side effects first appeared $(*)$ to the presence $(+)$ or absence $(-)$ of rifampicin antibodies. The three patients who developed thrombocytopenia are indicated by $P$; the one patient who developed nausea only is indicated by $\mathbf{N}$.

In Fig. 2 the length of treatment is related to the time of detection of rifampicin-dependent antibodies in the sera of the patients without side effects. Antibodies were detected in one patient the first time the serum was tested. Antibodies 


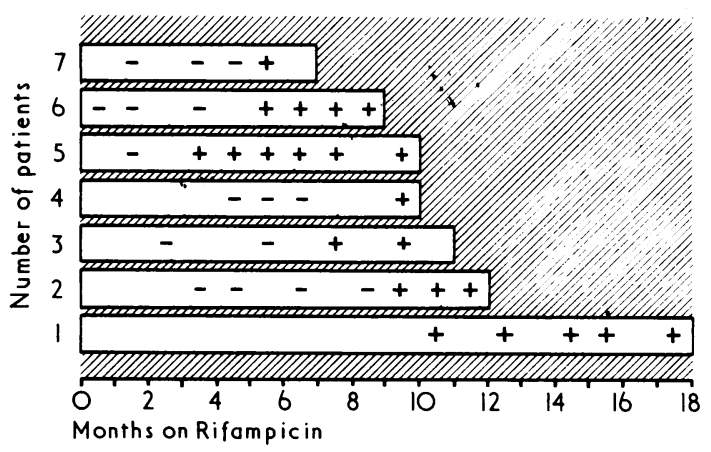

FIG. 2-Duration of treatment in the seven patients with antibody but no side effects. + indicates presence, - indicates absence of rifampicin antibodies.

appeared in the serum of the other six patients after a variable length of time. There is no relation between the length of time of treatment and the development of rifampicin-dependent antibodies, except that none were detected before the fourth month of treatment-that is, after starting the intermittent regimen. A comparison of the doses that patients received on a $\mathrm{mg} / \mathrm{kg}$ body-weight basis with the presence or absence of antibodies oblique/side effects showed no relation within this relatively narrow dose range $(13-26 \mathrm{mg} / \mathrm{kg}$ body weight).

There was no direct correlation between the antibody titres and the presence or absence of symptoms. Symptoms appeared in two patients who had low titres of antibody ( 2 and 2$)$, and one patient having a higher titre (32) did not complain of symptoms.

\section{Discussion}

Our short clinical experience with the 49 patients here reported supports previous opinions that rifampicin is a very valuable drug of great effectivity and of low toxicity when used on a daily basis at $600 \mathrm{mg}$. When used twice-weekly in $1,200-\mathrm{mg}$ doses, however, it is clearly potentially extremely dangerous. One-third of our patients, all on the intermittent regimen, developed antibodies to the drug even though very few of them had yet been exposed to a full course of treatment. Eleven $(22 \%)$ suffered some form of side effects leading to a withdrawal of the drug. A pyrexial syndrome, sometimes severe and once complicated by transient renal failure, developed in $8(16 \%)$; in only one of these were antibodies not detected. Three patients $(6 \%)$, one of whom also had pyrexia (Blajchman et al., 1970) and all of whom had antibodies, developed thrombocytopenia.

Reports from Chile first drew attention to thrombocytopenia occurring during treatment with large intermittent doses of rifampicin (Farga, 1970), while Burghard and Petitjean (1970) reported purpuric rashes with positive Shelley tests to rifampicin. Larbaoui et al. (1970) observed one patient with generalized purpura thought to be due to four months of treatment with rifampicin. Doyle et al. (1969) also found a high incidence of side effects (in 28 out of 74 patients, including six with fever) when rifampicin was given in high dosage $(1,800 \mathrm{mg})$ twice-weekly. These results compare very unfavourably with the comparable efficacy but lower toxicity, and much lower cost, of either thrice-weekly streptomycin plus isoniazid (Poole and Stradling, 1965, 1969) or twice-weekly streptomycin plus isoniazid (Polansky, 1970; Stradling and Poole, 1970) over a 15-month period after three months of daily treatment. The trial undertaken in Madras of intermittent streptomycin plus isoniazid given continuously from the start of treatment also showed a low incidence of side effects and high efficiency (Tuberculosis Chemotherapy Centre, Madras, 1964; Ramakrishnan et al., 1969).
In the present series a variety of drugs other than rifampicin were being taken by patients in the rifampicin and control groups. These included streptomycin, isoniazid, para-aminosalicylic acid, and ethambutol. There was no relation between these drugs and the presence or absence of rifampicin-dependent antibodies.

Rifampicin-dependent antibodies appeared more frequently in females than in males, but the numbers are too small to permit definite conclusions. Similarly, no relation between the incidence of these antibodies and the racial origin of the patients, their age, or the small variations in weight/dose relationship can be deduced from these small numbers. There was no pattern in the time of detection except that none were found before the fourth month of treatment, when all the patients had already started high-dose intermittent rifampicin. Since these antibodies could be detected for the first time as late as the 16th month of treatment it is clear that, if the treatment had continued, additional patients would probably have produced them and perhaps dangerous side effects.

The rifampicin-dependent antibodies bound complement to the surface of the patient's own or normal red cells in the presence of the drug. None of the patients, however, showed any evidence of red cell haemolysis in vivo. In a paper describing a case of immune thrombocytopenia due to quinine, Croft and his colleagues (1968) showed that the drug-related antibody could be easily detected in vitro by an indirect antiglobulin test when using red cells in the presence of the drug, even though their patient, like ours, showed no haemolysis in vivo. Presumably the amount of complement bound to the red cells in the presence of pharmacological amounts of the drug was insufficient to lead to increased red cell destruction.

Several drugs are known to cause thrombocytopenia by an immunological mechanism; these include stibophen, quinidine, quinine, and apronal. In the three patients in the present series with thrombocytopenia we were able to detect complement consumption in the presence of normal platelets and the drug in only one. However, the complement fixation test in which platelets were used has been shown to be less sensitive than the cytotoxic test where lymphocytes were used in the detection of platelet and white cell antigens (Svejgaard et al., 1967), and this lack of positive results may well be due only to the lack of sensitivity of the method.

The precise steps in the evolution of the drug-induced antibodies is uncertain, but it has been postulated that the drug acts as a hapten, which after it has bound to macromolecules in the plasma becomes antigenic and stimulates antibody formation. Furthermore, this hypothesis suggests that the antibodies are directed against the drug and that if the drug is given again hapten-antibody complexes will be formed. These haptenantibody complexes may either bind complement in the blood stream, which perhaps could lead to the febrile reactions, or be absorbed to the membrane of blood cells (red cells and platelets) and there bind complement. It is complement bound to the surface of the platelets that is thought to lead to their destruction.

We have found no reports of thrombocytopenia in patients receiving daily treatment with rifampicin. It seems likely that either the larger dose or the twice-weekly regimen or both determine or increase the immunological process.

There may well be a critical upper level of permissible dosage, exceeded in our series, below which the drug can be given safely and effectively on an intermittent basis. The finding that only small increases in dose can raise the serum concentration to disproportionately high levels (Canetti et al., 1968) is pertinent in this context and encourages trials of intermittent regimens in which doses lower than $1,200 \mathrm{mg}$ are used. A preliminary report by Decroix et al. (1969) of results with a 900-mg twice-weekly dose of rifampicin is very encouraging.

It is to be hoped that further large-scale trials of rifampicin, particularly those under the auspices of the British Medical Research Council, will elucidate the problems posed by our findings and determine an effective safe dose to use in inter- 
mittent regimens. Meanwhile we feel unable to continue to use rifampicin at a dose of $1,200 \mathrm{mg}$ twice-weekly.

We acknowledge the expert technical help of Miss Eleanor Lloyd and Mrs. Irene Owen, and the constructive suggestions of Professor D. A. Mitchison and Professor J. V. Dacie, Miss Angela Hartog and Miss Margaret Oliver helped with the collection of clinical data. The medical staffs of the Willesden Chest Clinic, the Central Middlesex Hospital, St. Charles's Hospital, and the Brompton Hospital kindly gave permission for patients under their care to act as controls. Dr. M. A. Thomson collected most of the control samples. Dr. M. A. Blajchman helped considerably with the early investigations. Miss P. Gammon estimated the actual content of the rifampicin solution. Lepetit Pharmaceuticals Ltd. generously supplied the rifampicin and a grant for technical assistance. Drs. Bergamini and Granger, of Lepetit Ltd., provided much valuable information.

\section{References}

Batten, J. (1969). Tubercle, 50, 294.

Blajchman, M. A., Lowry, R. C., Pettit, J. E., and Stradling, P. (1970). British Medical fournal, 3, 24.

Burghard, G., and Petitjean, R. (1970). Fournal de Medicine de Strasbourg, 1, 79.
Canetti, G., Le Lirzin, M., Porven, G., Rist, N., and Grumbach, F. (1968). Tubercle, 49, 367

Croft, J. D., et al. (1968). Annals of Internal Medicine, 68, 176.

Dacie, J. V., and Lewis, S. M. (1968). Practical Haematology, 4th ed. London, Churchill.

Dacie, J. V., and Worlledge, S. M. (1969). Progress in Hematology, 6, 82.

Decroix, G., et al. (1969). Revue de la Tuberculose et de Pneumologie, 33, 751

Dickinson, J. M., and Mitchison, D. A. (1970). Tubercle, 51, 82.

Doyle, J. A., et al. (1969). In XX International Tuberculosis Conference, New York, p. 25. New York, Excerpta Medica.

Farga, V. (1970). Personal communication.

Grumbach, F., Canetti, G., and Le Lirzin, M. (1969). Tubercle, 50, 280.

Grumbach, F., Canetti, G., and Le Lirzin, M. (1969). Tubercle, 50, 280.

Gyselen, A., et al. (1969). Acta Tuberculosea et Pneumologica Belgica, 60, 563.

Harris, J. W. (1956). Fournal of Laboratory and Clinical Medicine, 47, 760

Larbaoui, D., et al. (1970). Revue de la Tuberculose et de Pneumologie, 34, 559.

Lees, A. W., Asgher, B., Hasham, M. A., and Sinhar, B. N. (1970). British Fournal of Diseases of the Chest, 64, 90 .

Lesobre, R., Ruffinn, J., Teyssier, L., Achard, F., and Brefort, G. (1969). Revue de la Tuberculose et de Pneumologie, 33, 393.

Polansky, F. (1970). Bulletin of the International Union against Tuberculosis, 43, 295.

Poole, G. W., and Stradling, P. (1965). Tubercle, 46, 290.

Poole, G. W., and Stradling, P. (1969). British Medical fournal, 1, 82.

Ramakrishnan, C. V., et al. (1969). Tubercle, 50, 115.

Stradling, P., and Poole, G. W. (1970). Tubercle, 51, 44

Svejgaard, A., Kjerbe, K. E., and Kissmeyer-Nielsen, F. (1967). In Histocompatibility Testing, ed. E. S. Curtoni, P. L. Mattinz, and R. M. Tosi. Compatibility Testing, ed. E.

Tuberculosis Chemotherapy Centre, Madras. (1964). Bulletin of the World Health Organization, 31,247 Verbist, L., and Gyselen, A. (1968). American Review of Respiratory Diseases,
98, 923 .

\section{Effects of Poisoning on Serum Enzyme Activities, Coagulation, and Fibrinolysis}

British Medical fournal, 1971, 3, 347-350

\section{Summary}

Prolonged coma due to acute overdosage with hypnotic drugs is shown to be associated with a pronounced increase in the activity of serum creatine kinase and in the concentration of fibrin degradation products and with less pronounced abnormalities of other serum enzymes and of other indices of coagulation and fibrinolysis. Evidence is presented that skeletal muscle damage occurs and that this is related to the coagulation abnormality. These findings probably explain some of the non-specific features such as fever which commonly occur in recovery from severe poisoning.

\section{Introduction}

Elevation of certain serum enzyme activities is commonly associated with cellular damage. In poisoned patients (Brown et al., 1970) such changes may reflect specific organ damage due to drug toxicity or tissue injury which has been attributed to hypothermia (Maclean et al., 1968) or tissue hypoxia (Mandy

\section{Royal Infirmary, Edinburgh EH3 9YW}

N. WRIGHT, B.SC., M.R.C.P.ED., Medical Registrar, Regional Poisoning Centre

A. R. CLARKSON, M.R.A.C.P., Research Fellow, Medical Renal Unit, Department of Medicine

S. S. BROWN, PH.D., Senior Lecturer, University Department of Clinical Chemistry

V. FUSTER, M.D., Research Fellow, Edinburgh and South-East Scotland Regional Blood Transfusion Centre and Ackerman, 1970). As abnormalities in coagulation and fibrinolysis may play a part (Clarkson et al., 1970) in the development of renal damage in acute ischaemic renal failure, it seemed possible that similar mechanisms might contribute to tissue injury in poisoned patients. Accordingly, a study was undertaken of deeply unconscious poisoned patients whose recovery was not complicated by renal dysfunction. Changes in serum enzyme activities were correlated with abnormalities of coagulation and fibrinolysis and with clinical features.

\section{Patients and Methods}

The study was limited to patients who developed grade IV coma (Matthew and Lawson, 1970) after overdosage of hypnotic or tricyclic antidepressant drugs. The time of ingestion was determined as carefully as possible from the history, and the duration of coma was defined as the period between this time and that when the patient responded to loud vocal commands. All patients were treated by conservative supportive therapy and intensive nursing care, and particular attention was paid to monitoring pulse rate, blood pressure, rectal temperature, minute volume as measured by a Wright's spirometer, respiratory rate, and to the electrocardiogram. Patients at risk of aspirating were intubated. Positive-pressure ventilation was instituted if the minute volume was less than 4 litres or if arterial blood gas analysis indicated that there was serious impairment of gas exchange. Hypotension (systolic blood pressure $<80 \mathrm{~mm} \mathrm{Hg}$ ) was treated with metaraminol $(2.5 \mathrm{mg}$ intramuscularly); if this was ineffective plasma expanders were infused according to central venous pressure readings. No active measures to remove poisons were instituted except in one patient (Case 18, Table I) who was haemodialysed. 